\title{
Operando spectroelectrochemistry of redox state kinetics in water-oxidation $\mathrm{IrO}_{\mathrm{x}}$ electrocatalysts
}

\author{
Carlota Bozal-Ginestaa, Reshma R. Rao ${ }^{*}$, Camilo A. Mesa ${ }^{a}$, Xinyi Liua, Sam A.J. Hillmanº, Ifan E.L. \\ Stephens ${ }^{c}$, James R. Durranta* \\ aDepartment of Chemistry, Centre for Processable Electronics, Imperial College London, 80 Wood Lane, London W12 OBZ, UK \\ ${ }^{b}$ Department of Physics, Centre for Processable Electronics, Imperial College London, South Kensington Campus, London, SW7 \\ $2 A Z, U K$ \\ ${ }^{c}$ Department of Materials, Imperial College London, 80 Wood Lane, London W12 OBZ, UK \\ *reshma.rao@imperial.ac.uk \\ *j.durrant@imperial.ac.uk
}

Hydrous iridium oxides $\left(\mathrm{IrO}_{\mathrm{x}}\right)$ are the best oxygen evolution electrocatalysts available for operation in acidic environments. In this study, we employ time-resolved operando spectroelectrochemistry to investigate the redox states kinetics of $\mathrm{IrO}_{\mathrm{x}}$ electrocatalyst films for both water and hydrogen peroxide oxidation. Three different redox species involving $\mathrm{Ir}^{3+}$, $\mathrm{Ir}^{4+}$ and $\mathrm{Ir}^{4 . x}$ are identified spectroscopically and their concentrations are quantified as a function of applied potential. The generation of $\operatorname{Ir}^{4 . x+}$ states is found to be the potential determining step for catalytic water oxidation, whilst $\mathrm{H}_{2} \mathrm{O}_{2}$ oxidation is observed to be driven by the generation of $\mathrm{Ir}^{4+}$ states. The reaction kinetics for water oxidation, determined from the optical signal decays at open circuit, accelerate from $\sim 20 \mathrm{~s}$ to < $0.5 \mathrm{~s}$ with increasing applied potential above $1.3 \mathrm{~V} v \mathrm{~s}$. RHE (i.e. TOFs per active Ir state increasing from 0.05 to $2 \mathrm{~s}^{-1}$ ). In contrast, the reaction kinetics for $\mathrm{H}_{2} \mathrm{O}_{2}$ are found to be almost independent of the applied potential (increasing from 0.1-0.3 s-1 over a wider potential window), indicative of a first order reaction mechanism. These spectroelectrochemical data quantify the increase of both the density of active $\mathrm{Ir}^{4 . x+}$ states and the TOFs of these states with applied positive potential, resulting in the observed sharp turn on of catalytic water oxidation current. We reconcile these data with the broader literature while providing a new kinetic insight into $\mathrm{IrO}_{x}$ electrocatalytic reaction mechanisms, indicating a first order reaction mechanism for $\mathrm{H}_{2} \mathrm{O}_{2}$ oxidation driven by $\mathrm{Ir}^{4+}$ states, and a higher order reaction mechanism involving the co-operative interaction of multiple $\mathrm{Ir}^{4 \cdot . x+}$ states for water oxidation.

\section{Introduction}

Iridium-based oxides exhibit state-of-the-art activity and stability for the oxygen evolution reaction (OER), the step that limits the efficiency of emerging technologies such as proton-exchange membrane (PEM) electrolysers that convert renewable electricity into chemicals or fuels. ${ }^{1}$ In fact, iridium-based oxides are the only stable material with the ability to catalyse $\mathrm{O}_{2}$ evolution under the acid conditions of PEM electrolysers. ${ }^{1-10}$ To overcome the scalability issues related to the scarcity of iridium, ${ }^{11-13}$ researchers have focused on improving the OER activity of these materials per iridium atom, developing more porous and amorphous materials such as hydrous iridium oxides $\left(\mathrm{IrO}_{x}\right){ }^{6,}{ }^{6} 14-20$ These $\mathrm{IrO}_{x}$ materials reach higher OER activities per mass of iridium than crystalline $\mathrm{IrO}_{2}$, but have lower stability. ${ }^{16,21}$ The activity of $\mathrm{IrO}_{x}$, however, is difficult to understand because of their highly disordered structure and their complex redox chemistry. For instance, atom probe tomography and electrochemistry-mass spectrometry measurements have recently revealed that more than just the surface and single metal atoms are involved in redox reactions in OER electrocatalysts, but the 
relationship between redox states and states driving water oxidation remains elusive. ${ }^{22-27}$ In this context, operando techniques are a unique way to probe the redox states accumulated under catalytic conditions. Herein, we investigate $\mathrm{IrO}_{x}$ with time-resolved spectroelectrochemical methods, which we use to probe the different redox states of $\mathrm{IrO}_{x}$ involved in OER and the OER reaction kinetics.

Several different experimental and theoretical tools have been used to investigate the redox transitions and active sites for water oxidation on $\mathrm{IrO}_{x}$. Density functional theory studies on $\mathrm{IrO}_{2}(110)$ surfaces have proposed that the Ir centre is the active site, and binds oxygen relatively strongly, making the third proton-electron transfer step in the catalytic cycle rate limiting for water oxidation (i.e. ${ }^{*} O_{C U S}+$ $\mathrm{H}_{2} \mathrm{O} \rightarrow{ }^{*} \mathrm{OOH}_{\text {CUS }}+\mathrm{H}^{+}+\mathrm{e}^{-}$, where ${ }^{*}$ denotes an adsorbed reaction intermediate and CUS is a coordinatively unsaturated active site). ${ }^{28-31}$ Electrochemically, multiple redox peaks are detected prior to the onset of water oxidation catalysis, indicative of the presence of several redox transitions in $\mathrm{IrO}_{\mathrm{x}}$. Techniques such as X-ray, ${ }^{32,} 33$ Ultraviolet-Visible (UV-Vis) absorption, 28-31 and Raman ${ }^{34-36}$ spectroscopies have facilitated the identification of $\mathrm{IrO}_{x}$ species at different applied potentials under steady-state conditions. Raman spectroscopy on hydrous $\mathrm{IrO}_{x}$ have pointed to oxidation of $\mathrm{Ir}^{3+}$ centres to $\mathrm{Ir}^{4+}$ in the pre-catalytic potential range of $0.8-1.1 \mathrm{~V} v s$. RHE associated with deprotonation of hydroxyl groups. ${ }^{33}$ This observation is consistent with single crystal studies on $\operatorname{IrO}_{2}(110)$ in $0.1 \mathrm{M} \mathrm{KOH}$, where a redox peak at $\sim 0.9 \mathrm{~V} v s$. RHE was assigned on the basis of DFT calculations to the adsorption of a hydroxyl group on an Ir centre ( ${ }^{*} \mathrm{OH}_{C \cup S}$ ) which was then deprotonated to form oxo ( ${ }^{*} \mathrm{O}_{C u s}$ ) at higher potentials. Similarly, crystal truncation rod analysis combined with DFT on the isostructural, rutile $\mathrm{RuO}_{2}(110)$ electrocatalyst have shown that the redox features at $\sim 0.75 \mathrm{~V} v s$. $\mathrm{RHE}$ and $\sim 1.2 \mathrm{~V} v s$. RHE lead to deprotonation of adsorbed water on the coordinatively unsaturated Ru site ( ${ }^{*} \mathrm{OH}_{2} \mathrm{Cus}$ ) and ${ }^{*} \mathrm{OH}$ on the bridging $\mathrm{Ru}$ sites. ${ }^{29,37-43}$ However, the redox processes occurring on $\mathrm{IrO}_{x}$ at more positive potentials, where $\mathrm{O}_{2}$ evolution takes place are widely contested. While some authors have suggested further oxidation of the Ir centre to higher-oxidised redox states $(>4+), 26,44,45$ recent studies based on X-ray absorption spectroscopy suggest the formation of holes on surface oxo groups. ${ }^{34,46-48}$ In these steady-state spectroscopic measurements, however, it is not possible to quantify the concentration of active species present, to determine if they contribute to the OER reaction and to measure their reaction kinetics. This is especially important considering recent studies which have demonstrated the role of coverage of active species in determining the kinetics of water oxidation on $\mathrm{IrO}_{x} .^{26,44,45} \mathrm{Using} \mathrm{X}$-ray absorption and DFT calculations, the authors demonstrated that increasing potential increases the density of oxidized species ( ${ }^{*} \mathrm{O}_{\text {cus }}$ ), which can lower the activation energy for chemical O-O bond formation, the proposed rate-determining step, due to long-range interaction between adsorbates. ${ }^{22-27}$ In addition to the water oxidation kinetics, the definition of intrinsic activity, computed as a turnover frequency (TOF), relies on an accurate determination of the number of active sites or states. Commonly used activity metrics, such as gravimetric current density or specific current density normalized to the surface area, ${ }^{37,49}$ are not accurate in highly disordered materials like $\mathrm{IrO}_{\mathrm{x}}$ because of the difficulty to measure the real surface area, the presence of undercoordinated iridium atoms, and the potential participation of bulk iridium. Therefore, the activity of $\mathrm{IrO}_{x}$ can instead be directly related to the reaction rate of its redox states, their accumulation operando, and how these depend on the applied potential, topics which are the focus of this study.

By combining time-resolved spectroscopy and electrochemistry (TR SEC), we identify three redox transitions in $\mathrm{IrO}_{x}$ as a function of potential and quantify the concentration of the resulting redox states. This spectroelectrochemical approach has been successfully applied to investigate density of oxidized states on Ni-based electrocatalysts in alkaline solution and hematite photoelectrodes, ${ }^{26,44,45}$ but its application to $\mathrm{IrO}_{x}$ is particularly challenging because of its multiple redox states. In this work, we 
investigate electrodeposited $\mathrm{IrO}_{x}$ in $0.1 \mathrm{M} \mathrm{HClO}_{4}$ aqueous solution at $\mathrm{pH}$ 1.2. Spectroelectrochemical measurements are complemented by signal deconvolution methods and measurements of the optical signal lifetime after turning the applied potential off. The lifetimes and turn over frequency derived using this approach employ experimentally measured densities of redox states, and so do not rely on assumptions about the theoretical density of active sites. As such these studies enable direct measurement of intrinsic water oxidation kinetics of $\mathrm{IO}_{x}$ redox states, and thus provide a unique insight into the kinetics of electrochemical water oxidation in hydrous iridium oxide electrocatalysts.

\section{Materials and Methods}

\section{Electrodeposition of $\mathrm{IrO}_{\mathrm{x}}$}

A solution of iridium salt was prepared by dissolving $0.2 \mathrm{mmol}$ of $\mathrm{Ir}^{3+} \mathrm{Cl}_{3}$ hydrate (Fluorochem) and $2 \mathrm{mmol}$ of oxalic acid dehydrate (Sigma Aldrich) in $30 \mathrm{~mL}$ of water. The $\mathrm{pH}$ was adjusted to 10 with $\sim 5 \mathrm{mmol}$ of $\mathrm{Na}_{2} \mathrm{CO}_{3}$ (Sigma Aldrich, ReagentPlus $® \geq 99.0 \%$ ), making the solution turn from yellow to green. The volume of the solution was increased to $50 \mathrm{~mL}$ by adding more water. The solution was left to rest for 4 days at $35^{\circ} \mathrm{C}$ (the changes in its UV-Vis absorption are shown in Figure S0) and then stored in the refrigerator at $4^{\circ} \mathrm{C}$. The electrodeposition of $\mathrm{IrO}_{x}$ from this iridium solution was done by soaking a clean FTO on a glass substrate $\left(\sim 1 \mathrm{~cm}^{2}\right)$ and applying a current of $35 \mu \mathrm{A}$ for $\sim 1000$ s. Polyimide tape was attached on the FTO surface to limit the surface of the $1 \mathrm{rO} \mathrm{x}_{\mathrm{x}}$ to $\sim 1 \cdot 1 \mathrm{~cm}^{2}$. This preparation procedure is similar to that in the literature..$^{50,51}$

Scanning Electron Microscopy images of the resulting films were taken on a LEO GEMINI 1525 microscope using a $5 \mathrm{keV}$ electron beam. Note that no conductive coating was required. $\mathrm{X}$ ray photoelectron spectroscopy measurements were performed on a Thermo Scientific K-alpha+ instrument using Al Ka ( $\mathrm{hv}=1486.6 \mathrm{eV}$ ). The spectra are referenced against the adventitious carbon peak at $284.4 \mathrm{eV}$. Data was analysed using the CASA XPS package based on fitting parameters in references. ${ }^{37,49}$

\section{Spectroelectrochemistry}

Spectroelectrochemistry (SEC) measurements consisted in probing the absorbance of a sample with an Agilent Technologies Cary 60 UV-Vis spectrometer under different applied potential. The potential was controlled with a Metrohm Autolab PGSTAT101 potentiostat and applied between a platinum mesh (i.e. the counter electrode) and the sample (i.e. the working electrode). The potential at the working electrode was measured with respect to an $\mathrm{Ag} / \mathrm{AgCl}$ reference electrode saturated with $\mathrm{KCl}$. The absorption was recorded after applying the corresponding potential for $\sim 5$ minutes until the current was stable. Each spectrum was measured at least two times until it reached a steady state. The same results were also obtained using an alternative home-built setup integrated by an OceanOptics HL-2000-FHSA halogen light source and a OceanOptics Maya2000Pro spectrometer.

All the potentials are reported versus RHE and were $i R_{u}$ corrected. The potentials versus $\mathrm{Ag} / \mathrm{AgCl}$ saturated with $\mathrm{KCl}\left(E_{\mathrm{Ag} / \mathrm{AgCl}}\right)$ were calibrated against $\mathrm{RHE}$ and converted into potentials vs. $\mathrm{RHE}\left(E_{R H E}\right)$ as follows:

$$
\text { Equation I } \begin{aligned}
E_{R H E}=E_{A g / A g C l} & +E_{A g / A g C l}^{0}+\frac{2.30 \cdot R \cdot T}{Z \cdot F} \cdot p H \\
& =E_{A g / A g C l}+0.197+0.059 \cdot p H=E_{A g / A g C l}+0.2678
\end{aligned}
$$


Where $R$ is the ideal gas constant $\left(8.314 \mathrm{~J} \cdot \mathrm{mol}^{-1} \cdot \mathrm{K}^{-1}\right), T$ is the temperature $(298 \mathrm{~K}), F$ is the Faraday constant ( $96485 \mathrm{C} / \mathrm{mol}$ electrons), $z$ is the number of electrons transferred ( $1 \mathrm{~mol}$ electrons), and $E_{A g / A g C l}{ }^{0}$ is the standard potential of the $\mathrm{Ag} / \mathrm{AgCl}$ reference electrode saturated with $\mathrm{KCl}$ which has been calibrated versus RHE. The $\mathrm{pH}$ used is 1.2 .

All the potentials were corrected by subtracting $i \cdot R_{u}$, where $i$ is the current measured the corresponding potential and $R_{u}$ is the uncompensated resistance The resistance $R_{u}(\sim 35 \Omega)$ was calculated by fitting electrochemical impedance data in the $0.1-1 \mathrm{~Hz}$ range with the Randles circuit model.

\section{Step-Potential Spectroelectrochemistry}

In the step-potential spectroelectrochemistry measurements (SP-SEC), the absorption was probed during potential cycles consisting of two steps, as represented in Schemes 1 and S1. The potential was controlled with a PalmSens 3 potentiostat. In parallel, the probe light was produced with a $100 \mathrm{~W}$ Bentham tungsten lamp, and its wavelength was selected with two Horiba Scientific OBB monochromators placed before and after the sample. Additionally, a long-pass filter regulated by a mechanical colour wheel (FW101C Thorlabs) stood between the sample and the second monochromator. The probe light was detected by a silicon PIN photodiode (Hamamatsu S3071) and filtered by an optical transient amplifier (Costronics 2004). Finally, both the electrical and optical signals were processed with a digital phosphor oscilloscope (Tektronix DPO 3012) and a DAQ (National Instruments $X$ Series Multifunction). In the SP-SEC measurements, the electrochemical cell and electrodes used were the same as in the spectroelectrochemical experiments described above. This is the procedure followed in the experiments shown in Figures 4, 6, S2 and S5.

\section{Data Analysis and deconvolution}

The spectroelectrochemical model data was generated in Matlab R2019a with Equations 1-6, and it was optimised in the same program with the global minimisation tool GlobalSearch and the solver fmincon. These tools were set to find the minimum difference between the model and the real data, starting with a set of 200 initial trial points and examining a total of 1000 trial points, each point consisting of a different combination of values for the variables $A, \mu$ and $\sigma$ (Equation 6). One, two and three absorption contributions (Equation 1) were considered in the deconvolution of each data set, keeping the assumption that yielded the smallest error (Figures S2B and S8B). Finally, Lorentzian distributions were tried to model the concentration changes over potential (Equation 3), but Gaussian distributions were a better fit in all the cases.

The kinetics decays in Figures 4 and 5B were smoothed with a Savitzky-Golay filter, using polynomial order 2 applied to window of 50-500 points. To derive the lifetimes $r$, the optical signal decays were normalised and fit with a linear regression between 0 and $25 \%$ intensity decay.

\footnotetext{
Equation II $\Delta A=k \cdot t+c$

Equation III $\tau=1 / k$
} 
Where $\Delta A$ is the experimental differential absorption, $t$ is time, $k$ and $c$ are fit constants, and $t$ is the lifetime calculated from $k$.

\section{Results}

Hydrous iridium oxide films $\left(\mathrm{IrO}_{\mathrm{x}}\right)$ were prepared by electrodeposition following a wellestablished procedure. ${ }^{50,51}$ The films were electrodeposited on an FTO substrate by soaking the FTO in an aqueous solution with $4 \mathrm{mM} \mathrm{IrCl}_{3}$ (see SI for the details on the preparation and content of the solution), and by keeping a constant current of $35 \mu \mathrm{A}$ for $\sim 1000 \mathrm{~s}$. The resulting films consisted of amorphous $\mathrm{IrO}_{x}$ particles of a few micrometres in size, as supported by SEM (Figure 1A) and XPS (Figure S1A) data. The cyclic voltammetry of the $\mathrm{IrO}_{x}$ films, shown in Figure 1B, features three different redox transitions, which are considered to result from three different oxidative transitions. Two distinct redox peaks are observed at $\sim 0.95 \mathrm{~V}$ and, less pronounced, $\sim 1.25 \mathrm{~V} v s$. RHE (iR $R_{u}$ corrected). The relative size of the peaks is likely to be related to the starting state of the sample and the scanning rate. At a starting potential of $\sim 1.45 \mathrm{~V}$, the current increases exponentially, similar to state-of-the-art porous $\mathrm{IrO}_{x}$ electrocatalysts (Figure S1B) and is related to the OER electrocatalysis. The anodic component of the final redox transition is masked by the OER current, but a cathodic redox peak is visible at $\sim 1.45 \mathrm{~V} v s$. RHE. These multiple redox transitions and their overlap illustrates the complexity of the redox chemistry on $\mathrm{IrO}_{x}$ surfaces. Notably, the OER current density is comparable to previous reports on amorphous IrOx films. ${ }^{15,18,20}$

A

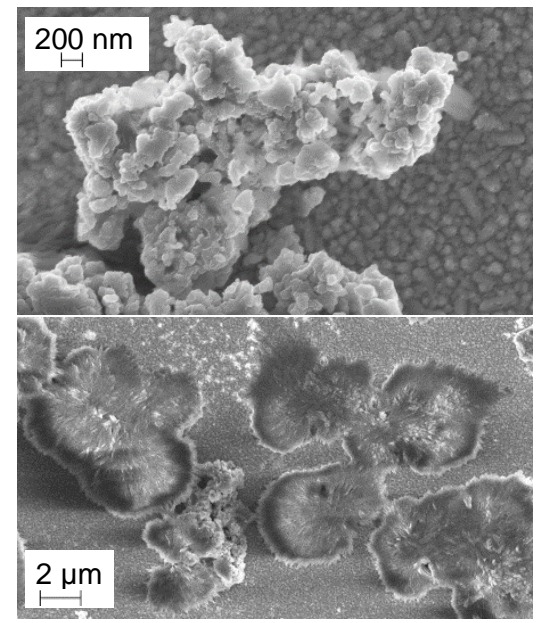

B

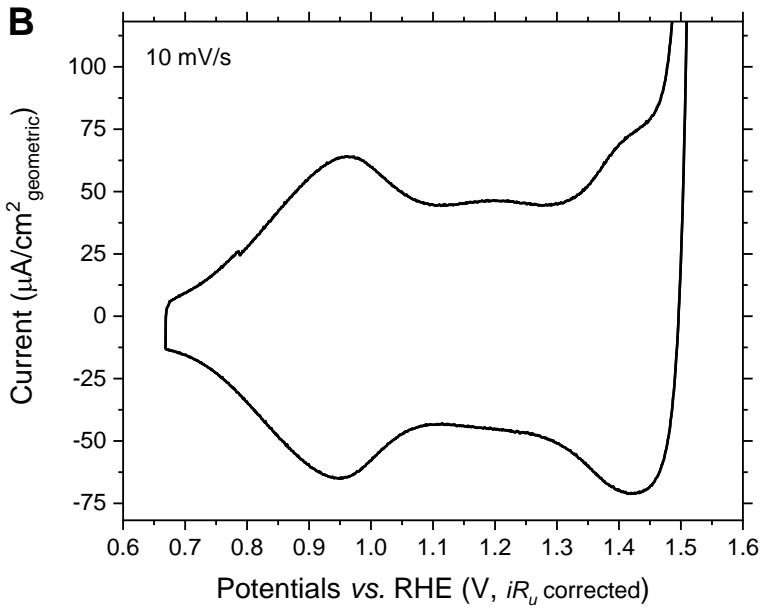

Figure 1. (A) SEM images of $\mathrm{IrO}_{x}$ on FTO. (B) Cyclic voltammetry of an $\mathrm{IrO}_{x}$ film electrodeposited on FTO. Measurements were made $\mathrm{d} 0.1 \mathrm{M} \mathrm{HClO}_{4}$ aqueous solution at $\mathrm{pH} 1.2$, with a scan rate of $10 \mathrm{mV} / \mathrm{s}$ and starting at $\sim 0.78 \mathrm{~V} v s$. RHE (iRu corrected).

To better identify the redox transitions of $\mathrm{IrO}_{\mathrm{x}}$ in the cyclic voltammetry above, we measured the absorption of $\mathrm{IrO}_{x}$ films as a function of potential in $0.1 \mathrm{M} \mathrm{HClO}_{4}$ aqueous solution at $\mathrm{pH}$ 1.2. The absorption was first measured at $0.66 \mathrm{~V} v$ s. RHE, below the open circuit potential of the pristine sample $(\sim 0.8 \mathrm{~V} v s$. RHE) and was subsequently monitored at increasingly oxidising applied potentials until 
$1.52 \mathrm{~V}$ vs. RHE, which is within the oxygen evolution regime. In this potential range, differential absorption spectra were calculated relative to the absorption at $0.66 \mathrm{~V}$ vs. RHE. Broad absorption changes were observed across the visible range (Figure 2A): a band at $600 \mathrm{~nm}$ dominated the differential spectrum at low oxidation potentials, and two new features at $800 \mathrm{~nm}$ and $480 \mathrm{~nm}$ appeared above $1.11 \mathrm{~V}$ and $1.36 \mathrm{~V}$ vs. RHE respectively (Figure $2 \mathrm{~B}$ ). These optical changes coincide with the redox transitions detected in the potential range from $\sim 0.66 \mathrm{~V}$ vs RHE to $1.52 \mathrm{~V}$ vs RHE in the cyclic voltammetry (Figure 1). In contrast, the bare FTO substrate did not show any optical change in the same potential range (Figure S2). These results therefore show that the three redox transitions above the open circuit potential have characteristic absorption signals, similar to the electrochromism of other IrOx films reported in the same potential range. ${ }^{28,29,41,50,52,53}$ Below, we go one step further, deconvolving these absorption trends to quantitatively analyse the concentrations of the different redox states involved, a useful approach to circumvent the overlap between redox and catalytic processes.
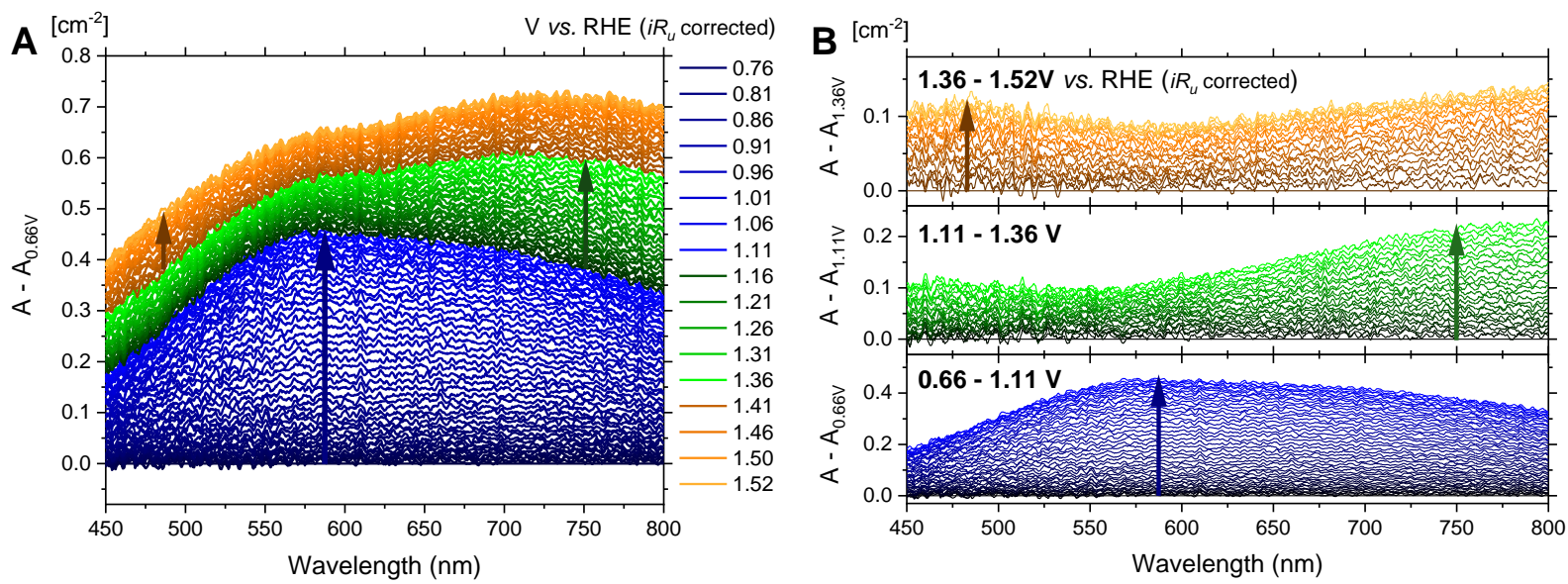

Figure 2. Absorption changes of $\mathrm{IrO}_{x}$ upon applying an oxidative potential in $0.1 \mathrm{M} \mathrm{HClO}_{4}$ aqueous solution at $\mathrm{pH}$ 1.2. Absorption changes calculated with respect to (A) $0.66 \mathrm{~V}$, and (B) $0.66 \mathrm{~V}$ (bottom), 1.11V (middle), and 1.36V (top) vs. RHE, (iRu corrected). Spectra were measured every $50 \mathrm{mV}$.

To investigate individual redox transitions of $\mathrm{IrO}_{\mathrm{x}}$, we deconvoluted the absorption changes detected in Figure 2 as a function of potential into the corresponding redox states, and the concentration of these redox states as a function of potential. Model data $\Delta A_{\text {fit }}(E, \lambda)$ was built by making four approximations, where $\Delta A$ is the absorption difference as a function of the potential $E$ and the wavelength $\lambda$. First, taking into account the data above, we assumed three different contributions $A_{i}(E, \lambda)$ to the absorption (Equation 1), where $i$ is the redox transition number. Assuming fewer than three contributions was not enough to describe the experimental data accurately. Second, following the Lambert-Beer law, the absorption changes were considered linearly proportional to the concentration of the redox state formed at each transition (Equation 2), $C_{i}(E)$. Third, the concentration of the redox state formed at each potential was approximated as a Gaussian distribution over potential (Equation 3 ), which is expected to be a good representation of capacitive redox transitions but a less accurate approximation for the onset of catalytic and Faradaic processes. Fourth, the differential absorption coefficients $\varepsilon_{i}(\lambda)$ were calculated from the experimental absorption at three different potentials following 
Equations 1-2 (Equations 4-6). The model data was fit to the experimental data by adjusting the centre $(\mu)$, width $(\sigma)$ and amplitude $(A)$ of the Gaussian distributions $(A \cdot \operatorname{Gaussian}(\mu, \sigma))$, corresponding to the concentration changes over potential of each redox state. The process of fitting sought to minimise the difference between the experimental and the model data $\left(\left|\Delta A_{\text {real }}(E, \lambda)-\Delta A_{\text {fit }}(E, \lambda)\right|\right)$ across all the wavelengths and potentials (see SI for more details on the optimisation method). As a result, this procedure allowed separating the contributions to the absorption of the three different redox transitions with a minimal error (Figure S3).

Equation $1 \quad \Delta A_{f i t}(E, \lambda)=A_{1}(E, \lambda)+A_{2}(E, \lambda)+A_{3}(E, \lambda)$

Equation $2 \quad A_{i}(E, \lambda)=C_{i}(E) \cdot \varepsilon_{i}(\lambda)$

Equation $3 \quad C_{i}(E)=\int_{0.55}^{E}\left(\frac{\mathrm{d} C}{\mathrm{~d} E}\right) \mathrm{d} E=\int_{0.55}^{E} A \cdot \operatorname{Gaussian}(\mu, \sigma) \mathrm{d} E$

Equation $4 \quad \varepsilon_{1}(\lambda)=\frac{\Delta A_{\text {real }}(0.8 \mathrm{~V}, \lambda)}{C_{1}(0.8 \mathrm{~V})}$

Equation $5 \quad \varepsilon_{2}(\lambda)=\frac{\Delta A_{\text {real }}(1 V, \lambda)-C_{1}(1 V) \cdot \varepsilon_{1}(\lambda)}{C_{2}(1 V)}$

Equation $6 \quad \varepsilon_{3}(\lambda)=\frac{\Delta A_{\text {real }}(1.5 \mathrm{~V}, \lambda)-C_{1}(01.5 \mathrm{~V}) \cdot \varepsilon_{1}(\lambda)-C_{2}(1.5 \mathrm{~V}) \cdot \varepsilon_{2}(\lambda)}{C_{3}(1.5 \mathrm{~V})}$

As a result of the deconvolution described above, the differential absorption coefficients and the concentration distributions of redox states were obtained for each redox transition (Figure 3A). From these results, it becomes clear that the maximum concentration change of the three redox states resulting from the different redox transitions takes place at $\sim 0.9 \mathrm{~V}, \sim 1.3 \mathrm{~V}$ and $\sim 1.5 \mathrm{~V}$ vs. RHE (iRu corrected), and have characteristic differential absorptions at 600,800 and $460 \mathrm{~nm}$ respectively. This evidence is in agreement with the dark-blue coloration reported for $\mathrm{IO}_{x}$ at $0.8-1.3 \mathrm{~V}$ vs. RHE, which is independent of $\mathrm{pH}$ and has little current-voltage hysteresis. ${ }^{41,52,53}$ These optical transitions have traditionally been assigned to an intervalence charge transfer within the iridium $d$ orbitals derived from the oxidation of $\mathrm{Ir}^{3+}$ to $\mathrm{Ir}^{4+}$ resulting from deprotonation of hydroxyl groups coordinated to the Ir centre

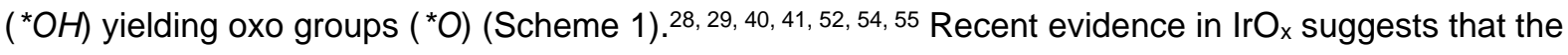
redox transitions below the potential range where the electrocatalytic current starts increasing are due to the oxidation of $\mathrm{Ir}^{3+}$ to $\mathrm{Ir}^{4+}$ in different steps. ${ }^{33,56} \mathrm{In}$ parallel, it has been shown that molecular iridium dimers can form stable redox states including both $\mathrm{Ir}^{3+}$ and $\mathrm{Ir}^{4+}$ or $\mathrm{Ir}^{4+}$ and $\mathrm{Ir}^{5+}$ that have characteristic absorption features in the visible range. ${ }^{30}$ This evidence is compatible with our observation of two redox transitions with different absorption spectra between the starting open circuit potential and potentials when the electrocatalytic current starts increasing (detected in the $\mathrm{CV}$ in Figure 1 and represented more precisely in Figure 3A), which are then assigned to the oxidation of $\mathrm{Ir}^{3+}$ into $\mathrm{Ir}^{4+}$ in two steps. Redox transition 3 is then assigned to the oxidation of $\mathrm{Ir}^{4+}$, most likely leading to the formation of oxidised oxygen species. $6,15,20,37,42,43$ Therefore, we denotate $\operatorname{Ir}\left(\mathbf{3}_{+}\right)$the starting state of the material, $\operatorname{Ir}(\mathbf{3} \cdot \mathbf{x +})$ 
the redox state resulting from the redox transition $1, \operatorname{Ir}(4+)$ the redox state from the redox transition 2 , and $\operatorname{Ir}(\mathbf{4} . \mathbf{x}+)$ the redox state from redox transition 3, as illustrated in Scheme 1. This terminology aims at representing the iridium oxidation numbers present at each redox state, but not their exact stoichiometry $;{ }^{57}$ we use it from here onwards to refer to the four redox states.

A

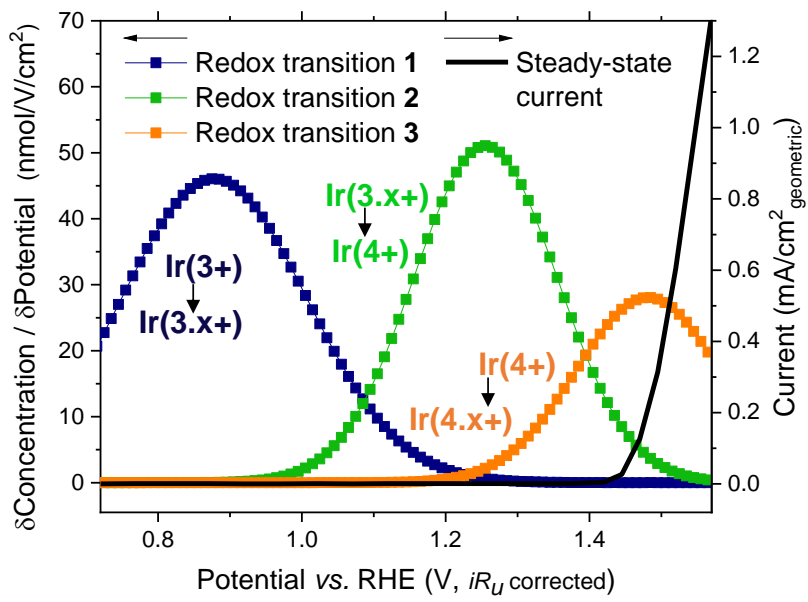

B

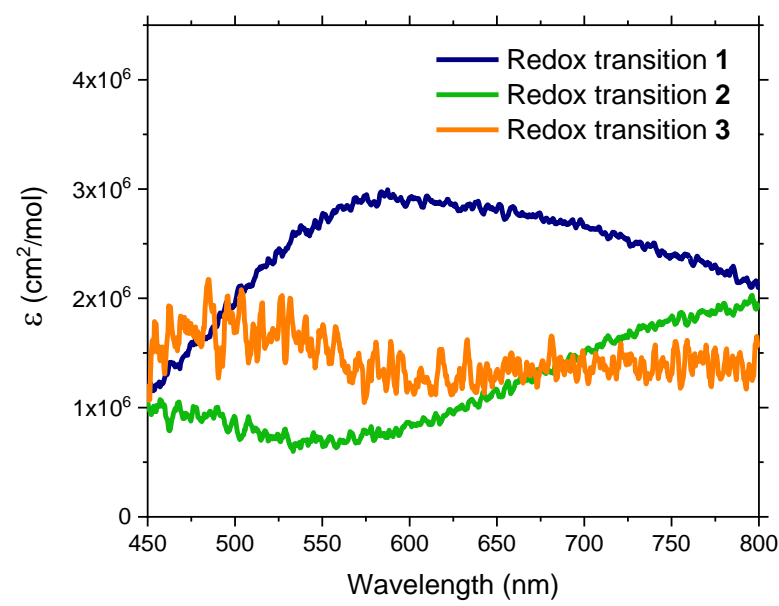

Figure 3. (A) Change in the concentration of redox states over potential in contrast with the steady state current under constant applied potential, and (B) differential absorption coefficients corresponding to the deconvolution and calibration of the three redox transitions fit to the spectroelectrochemical data in Figure 2.

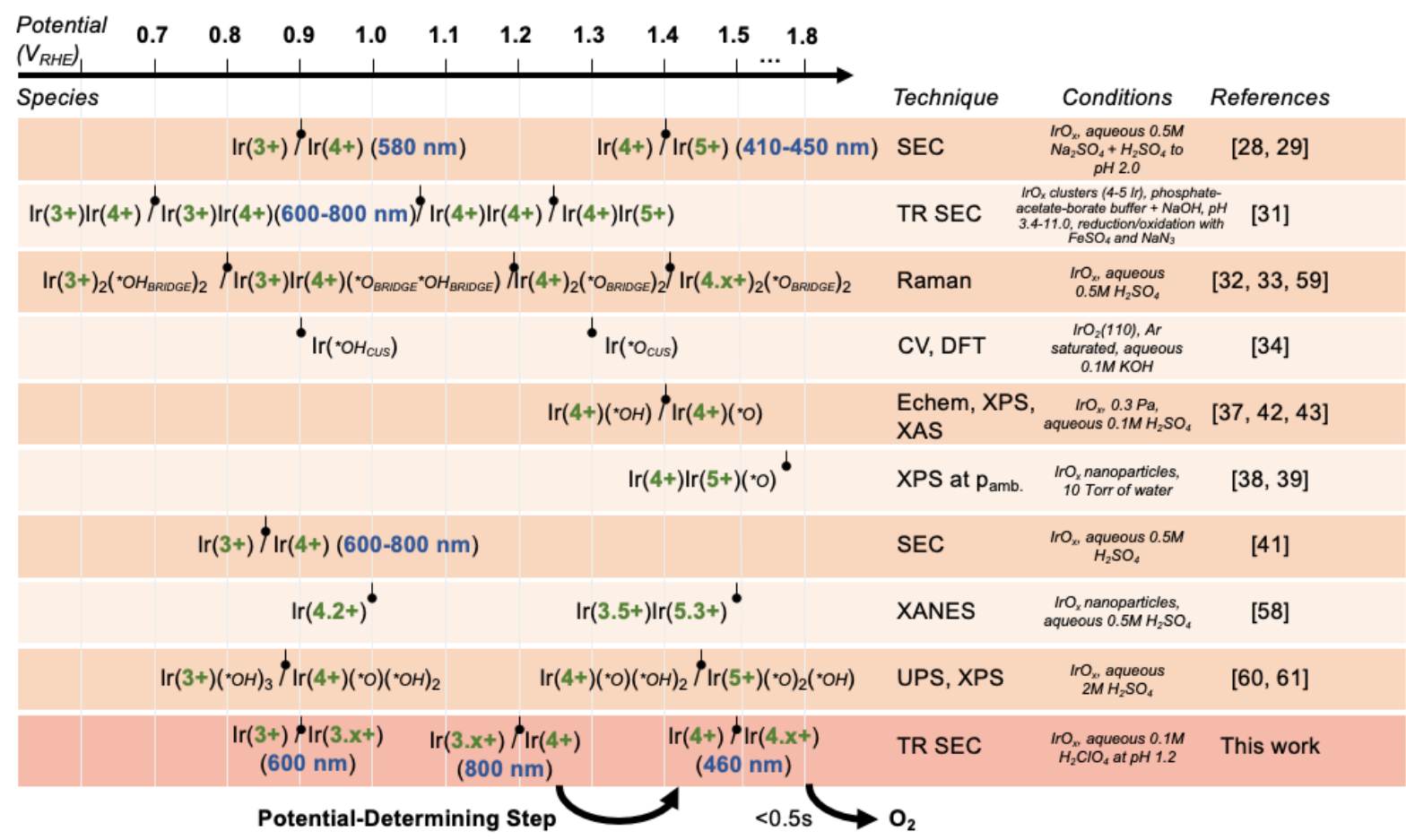

Scheme 1. Role and kinetics of the $\mathrm{IrO}_{x}$ redox states in the OER mechanism, as detected in this work and compared to the literature. ${ }^{28,} 29,31-34,37-39,41-43,58-61$ The abbreviations of the techniques stand for: $C V=$ cyclic voltammetry, $D F T=$ density functional theory, $X A N E S=\mathrm{X}$-ray absorption near edge structure, Echem $=$ electrochemistry, $X P S=\mathrm{X}$-ray photoelectron spectroscopy, $X A S=\mathrm{X}$-ray absorption spectroscopy, $\mathrm{SEC}=$ spectroelectrochemistry, TR SEC = time-resolved spectroelectrochemistry; pamb. $=$ ambient pressure, UPS $=$ ultraviolet photoelectron spectroscopy. The oxidation number of iridium is indicated in green, the maximum absorption wavelength is written in blue, and adsorbed species are identified with *, with the subscript CUS and $B R I D G E$ indicating whether they are adsorbed at a coordinatively unsaturated site or in the bridging position. 
Because the concentrations and differential absorption coefficients derived from the previous deconvolution have arbitrary units, these parameters were calibrated with the experimental values of $\varepsilon_{1}(600 \mathrm{~nm}), \varepsilon_{2}(800 \mathrm{~nm})$ and $\varepsilon_{3}(460 \mathrm{~nm})$, as shown in Figure 3B. These differential absorption coefficients were estimated from a combination of pulse voltammetry and transient absorption measurements at potentials where only one redox transition takes place. To quantify the change in the concentration of states over potential, pulse voltammetry measurements were performed during potential cycles where two potentials with a difference of $50 \mathrm{mV}$ were applied in consecutive steps of $5 \mathrm{~s}$ and $8 \mathrm{~s}$ (Scheme S1). When changing the applied potential, the current peaks and, after $\sim 1 \mathrm{~s}$, stabilises (Figure S5A). This current spike is assumed to be mostly due to the oxidation and reduction of states in $\operatorname{IrO}$. In the case of the third redox transition, which occurs in parallel to OER, the electrochemical oxidation is assumed to be faster than the catalytic OER, as verified later with kinetic measurements. Therefore, we integrated the current spike over time, having subtracted the steady-state current, in order to estimate the moles of redox states formed at each potential interval. For each redox transition, we measured the extracted charges at potential intervals around $0.9 \mathrm{~V}, 1.2 \mathrm{~V}$ and $1.5 \mathrm{~V}$ where we expect the charges to derive only from redox transitions 1, 2 and 3 respectively, as deduced from Figure 3A. To calculate the differential absorption coefficients of the redox states formed at each redox transition, the deconvoluted absorptions changes at the maximum absorption wavelength $(600,800$ and $460 \mathrm{~nm}$ for the redox transitions 1, 2 and 3 respectively, Figure S4) were plotted against the moles of extracted charges removed from the film for each redox transition (Figures S4B-D). The slope of the linear regression was taken as the differential absorption coefficient $\left(\varepsilon_{i}\left(\lambda_{\text {max. }}\right)\right.$ in Equation 2$)$, corresponding to the differential absorption change per one-electron oxidation during each redox transition. Having calculated $\varepsilon_{1}(600 \mathrm{~nm}), \varepsilon_{2}(800 \mathrm{~nm})$ and $\varepsilon_{3}(460 \mathrm{~nm})$, the differential absorption coefficients and the concentration changes over potential were calibrated accordingly in Figure 3A-B following Equation 2. It is apparent from Figure $3 \mathrm{~A}$ that the area below the concentration distributions, resulting from one-electron oxidations, is similar in redox transitions 1 and 2 , and larger than in redox transition 3 . This indicates that the $3^{\text {rd }}$ redox transition involves smaller amount of charges than the previous ones, which is probably related to either an incomplete oxidation process or to a relatively smaller concentration of the resulting redox state compared to less-oxidised redox states.

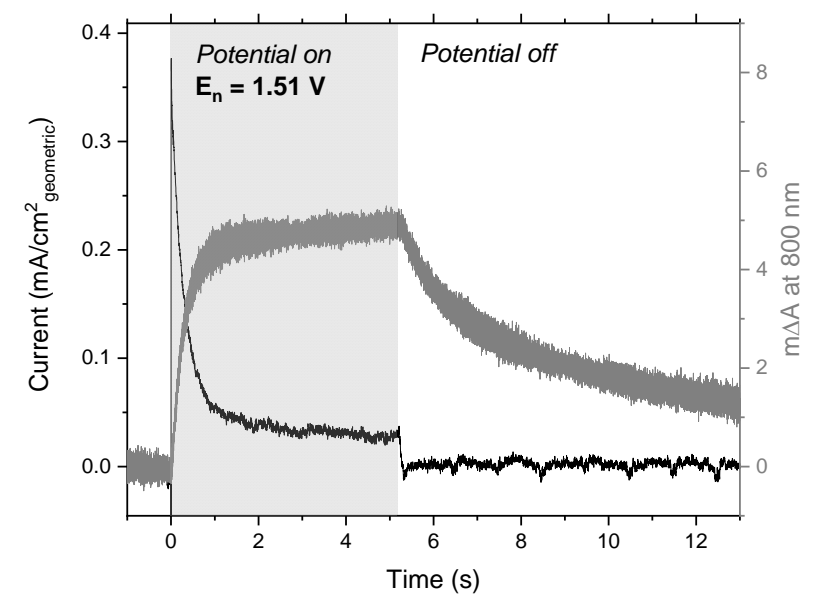

Figure 4. Transient current and absorption difference $\Delta A$ at $800 \mathrm{~nm}$ of $\mathrm{IrO}_{\mathrm{x}}$ in one potential step between OCP (when the potential off) and an applied potential of $1.51 \mathrm{~V}$ vs. RHE in a SP-SEC measurement. 
Once the potential and absorption of the different redox states have been identified and assigned, we move on to investigate their reaction kinetics. With this goal, we measured the decay of the optical signal after turning the applied potential off in the same $0.1 \mathrm{M} \mathrm{HClO}_{4}$ aqueous solution at $\mathrm{pH}$ 1.2. These measurements, which we denotate as step-potential spectroelectrochemistry (SP-SEC), consisted of regular two-step cycles, where the potential was applied for $5 \mathrm{~s}$ and was turned off for $8 \mathrm{~s}$. During these potential cycles, the current and absorption changes were measured simultaneously as exemplified in Figure 4. The maximum absorption after applying a potential $E_{n}$ for $4 \mathrm{~s}$ at different wavelengths and potentials is shown in Figure $5 \mathrm{~A}$. A significant absorption change between $E_{n}$ and OCP was only detected at $E_{n}>\sim 1 \mathrm{~V} v s$. RHE (iRu corrected), consistent with the fact that the resting OCP in these SP-SEC measurements after turning the potential off was around $1 \mathrm{~V} v s$. RHE. Under a constant applied potential, the absorption stabilised within 1-2s (Figure 4). After 4s, the differential spectrum of IrO $x$ mostly corresponds to the absorption changes associated to the redox transition 2 and the redox transition 3 (Figure $5 \mathrm{~A}$ in green and orange). Therefore, the absorption change upon applying a potential from OCP must be related to the oxidations $\operatorname{Ir}(\mathbf{3 . x +}) \rightarrow \operatorname{Ir}(\mathbf{4 +})$ (redox transition 2) and $\operatorname{Ir}(\mathbf{4 +}) \rightarrow \operatorname{Ir}(\mathbf{4} . \mathbf{x}+)$ (redox transition 3). In parallel, the absence of the characteristic absorption features of the oxidation $\operatorname{Ir}(\mathbf{3} . \mathbf{x}+) \rightarrow \operatorname{Ir}\left(\mathbf{4}^{+}\right)$(redox transition 1 ) is in agreement with the resting OCP of $\sim 1 \mathrm{~V} v s$. RHE, which is above the redox peak potential of the redox transition 1 (Figure $3 \mathrm{~A}$ ). When turning the potential off, the optical signals decay as shown in Figure 5B for the $800-\mathrm{nm}$ signal, with the decay kinetics being independent of the probe wavelength. The decay becomes faster for potentials upto $1.4 \mathrm{~V} v \mathrm{~s}$. RHE, plateauing at around $1.5 \mathrm{~V}$ vs. RHE (Figure 5B). This decay can be attributed to the depletion of $\operatorname{Ir}(\mathbf{4 . x +})$, the redox state formed $>1 \mathrm{~V}$. Its faster decay after turning off at more positive applied potentials implies a greater reactivity of this state at increasing potentials. Furthermore, $\operatorname{Ir}(\mathbf{4} . \mathbf{x +})$ is the predominant state at potentials when the current density increases due to OER (Figure $3 \mathrm{~A}$ ), which directly relates this state with the OER catalysis. Considering the absorption changes between the potential steps described above, in the absence of applied potential, $\operatorname{Ir}(\mathbf{4} . \mathbf{x +})$ is reduced back mostly to $\operatorname{Ir}(\mathbf{4 +})$ but also $\operatorname{Ir}(\mathbf{3} . \mathbf{x +})$. Combined, these results indicate that the redox state $\operatorname{Ir}\left(4 . x_{+}\right)$is the most reactive $\mathrm{IrO}_{x}$ state in water, and that this state probably yields $\mathrm{O}_{2}$, consequently forming $\operatorname{Ir}(\mathbf{4 +})$ and $\operatorname{Ir}(\mathbf{3} \cdot \mathbf{x +})$.
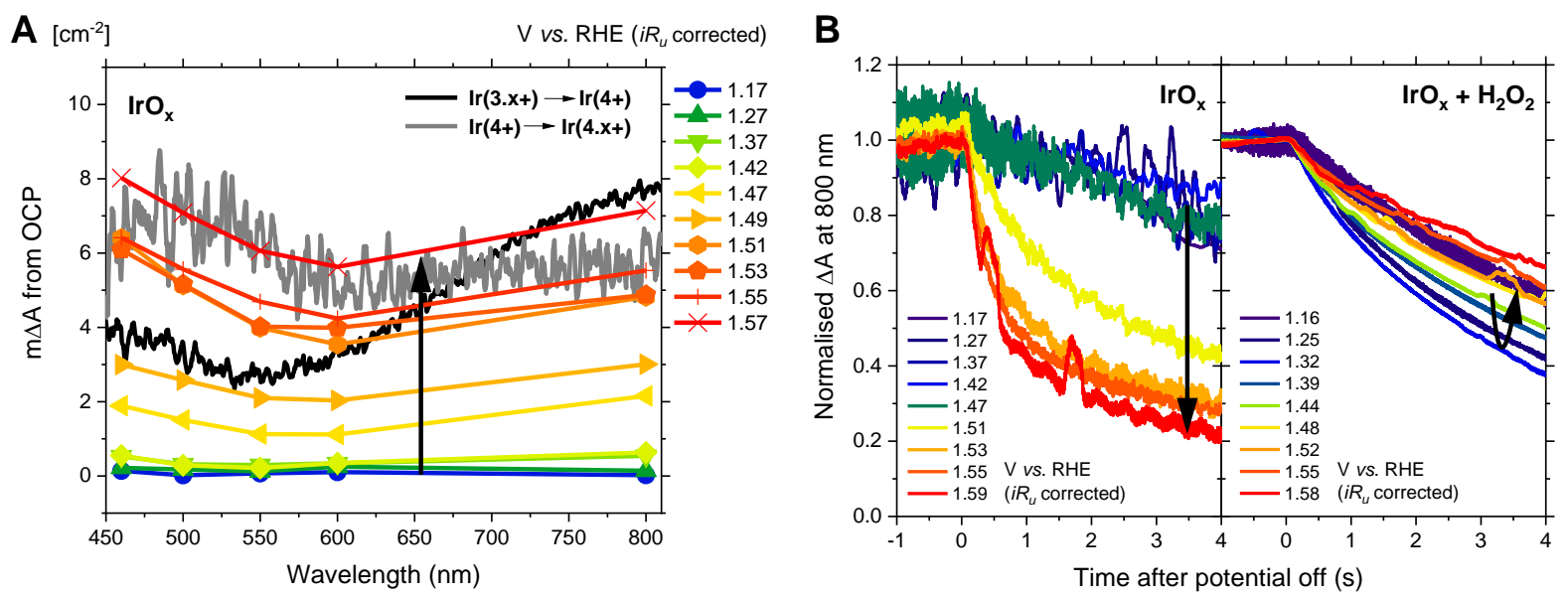

Figure 5. (A) Maximum absorption of $\mathrm{IrO}_{x}$ after applying a potential for $4 \mathrm{~s}$ compared to the deconvoluted differential absorption of redox transitions $2\left(\mathbf{I r}(\mathbf{3} \cdot \mathbf{x}+) \rightarrow \operatorname{Ir}\left(\mathbf{4}_{+}\right)\right)$and $3(\mathbf{I r}(\mathbf{4 +}) \rightarrow \mathbf{I r}(\mathbf{4} \cdot \mathbf{x}+))$. (B) Normalised absorption decay after turning the applied potential off in $0.1 \mathrm{M} \mathrm{HClO}_{4}$ aqueous solution at $\mathrm{pH} 1.2$ (left) and with additional $20 \mathrm{mM}$ of $\mathrm{H}_{2} \mathrm{O}_{2}$ (right). 
For a more in-depth analysis of the reactivity of the redox states detected, hydrogen peroxide was added to the electrolyte to investigate how its kinetically less challenging two-electron oxidation into $\mathrm{O}_{2}$ affects the steady-state concentration and kinetics of the $1 \mathrm{rO} \mathrm{O}_{\mathrm{x}}$ redox states. We measured the steady-state current of the same $\mathrm{IrO}_{x}$ sample in $0.1 \mathrm{M} \mathrm{HClO}_{4}$ at $\mathrm{pH} 1.2$ with $20 \mathrm{mM} \mathrm{H}_{2} \mathrm{O}_{2}$ (Figure $6 \mathrm{~A}$ ), which shows higher electrocatalytic currents above $1.1 \mathrm{~V}$ vs. RHE with $\mathrm{H}_{2} \mathrm{O}_{2}$ than without. We then measured the absorption of $\mathrm{IrO}_{x}$ at different potentials in the presence of $\mathrm{H}_{2} \mathrm{O}_{2}$, observing broadly the same trends as in $\mathrm{IrO}_{x}$ without $\mathrm{H}_{2} \mathrm{O}_{2}$ (Figure S6). Following the same deconvolution procedure as before (Equations 1-6 and $\mathrm{SI}$ ), the spectroelectrochemical data was fit with different absorption contributions or redox transitions (Equation 1, Figure S7). Very similar results were obtained from fitting both twoand three-absorption contributions, with the $3^{\text {rd }}$ one being negligible. Figure $6 \mathrm{~B}$ shows the deconvoluted concentration changes over potential and the absorption changes related to the two redox transitions detected in $\mathrm{H}_{2} \mathrm{O}_{2}$, compared to the two first redox transitions without $\mathrm{H}_{2} \mathrm{O}_{2}$. It is apparent that redox transitions 1 and 2 are very similar in both conditions, with maximum absorption changes at 600 and $800 \mathrm{~nm}$ taking place around 0.9 and $1.3 \mathrm{~V} \mathrm{vs.} \mathrm{RHE} \mathrm{(} i R_{u}$ corrected) respectively. This indicates that the nature of the redox states are most likely the same in these conditions and that $\operatorname{Ir}\left(\mathbf{3}^{+}\right) \rightarrow \operatorname{Ir}\left(\mathbf{4} . \mathbf{x}^{+}\right)$(redox transition 1) and $\operatorname{Ir}(\mathbf{3} . \mathbf{x}+) \rightarrow \operatorname{Ir}(\mathbf{4 +})$ (redox transition 2) take place, while $\operatorname{Ir}(\mathbf{4} . \mathbf{x}+)$ (resulting from redox transition 3) probably does not accumulate enough to be detected. In the presence of $\mathrm{H}_{2} \mathrm{O}_{2}$, the steadystate current starts increasing above $1.1 \mathrm{~V}$ and overlaps with the redox transition 2, where $\operatorname{Ir}\left(3 . \mathbf{x}_{+}\right)$is oxidised to $\operatorname{Ir}(4+)$. Furthermore, the current above $\sim 1.5 \mathrm{~V}$ vs. $\mathrm{RHE}$ is larger with $\mathrm{H}_{2} \mathrm{O}_{2}$ than without, which could be due to the coexistence of $\mathrm{H}_{2} \mathrm{O}_{2}$ and $\mathrm{H}_{2} \mathrm{O}$ oxidation, the extra current deriving from the oxidation of the additional $\mathrm{H}_{2} \mathrm{O}_{2}$. This would indicate that the redox state $\operatorname{Ir}(\mathbf{4 +})$ can oxidise $\mathrm{H}_{2} \mathrm{O}_{2}$, while $\operatorname{Ir}(\mathbf{4} . \mathbf{x +})$ is required to oxidise water.

A

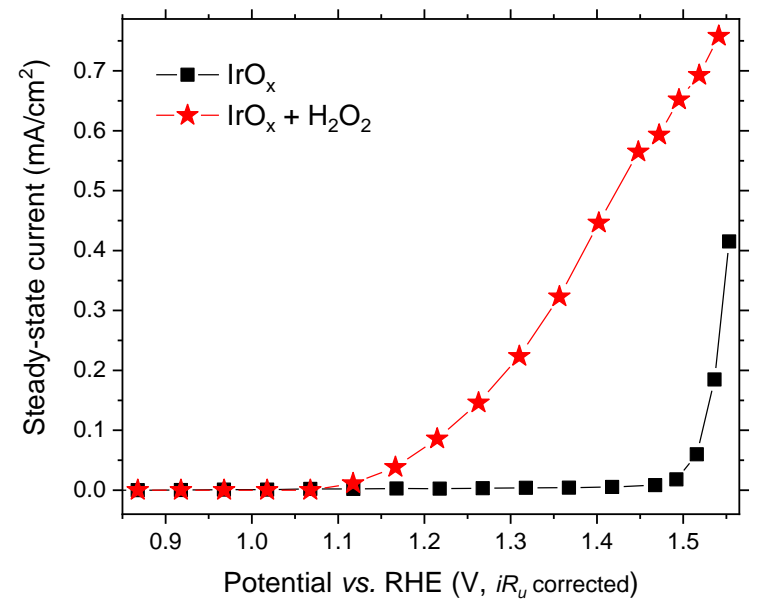

B $--\mathrm{IrO}_{\mathrm{x}}-\star-\mathrm{IrO}_{\mathrm{x}}+\mathrm{H}_{2} \mathrm{O}_{2}$
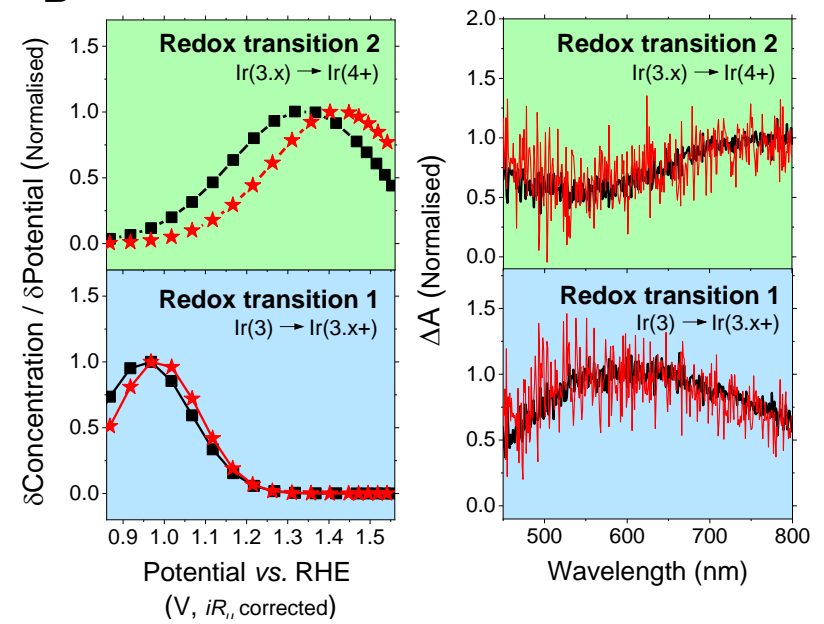

Figure 6. (A) steady-state current and (B) Deconvoluted differential absorption and concentration changes of $1 \mathrm{rO} \times$ with and without $20 \mathrm{mM} \mathrm{H}_{2} \mathrm{O}_{2}$ in $\mathrm{HClO}_{4}$ aqueous solution at $\mathrm{pH} 1.2$, where $\delta$ Concentration/DPotential is the concentration of the redox state formed at each potential. The absorption and currents were measured under constant applied potentials every $0.05 \mathrm{~V}$.

Once the redox transitions of $\mathrm{IrO}_{x}$ in the presence of $\mathrm{H}_{2} \mathrm{O}_{2}$ were identified, we measured their kinetics in these conditions. The same SP-SEC measurement done with $\mathrm{IrO}_{x}$ in acid media was repeated after adding $20 \mathrm{mM} \mathrm{H}_{2} \mathrm{O}_{2}$ (Figure 4). Under increasingly oxidising potentials, the differential 
absorption spectra versus OCP have larger absorption changes at $800 \mathrm{~nm}$ with than without $\mathrm{H}_{2} \mathrm{O}_{2}$ (see Figures $\mathrm{S} 9$ and $5 \mathrm{~A}$, with and without $\mathrm{H}_{2} \mathrm{O}_{2}$ respectively). This is the characteristic feature of the redox transition 2 and the oxidation $\operatorname{Ir}(\mathbf{3} . \mathbf{x}+) \rightarrow \operatorname{Ir}(\mathbf{4 +})$, which means that a larger concentration of $\operatorname{Ir}(\mathbf{4 +})$ is formed under applied potential and depleted under OCP in the presence of $\mathrm{H}_{2} \mathrm{O}_{2}$ than without. Furthermore, after turning the potential off, the potential dependence of the decay kinetics of the optical signals are different with $\mathrm{H}_{2} \mathrm{O}_{2}$, becoming faster between 1.1 and $1.4 \mathrm{~V}$, but slowing down after $1.4 \mathrm{~V}$ vs. $\mathrm{RHE}$ ( $i R_{u}$ corrected) (Figure 5B). To better compare the signal lifetimes with and without $\mathrm{H}_{2} \mathrm{O}_{2}$, we fit the normalised decays between $\triangle A=1$ and $\triangle A=0.75$ after turning the applied potential off with an initial slope linear regression, when the decay in the potential of the electrode is not significant. The lifetimes were then calculated as the inverse of the slope extracted from the linear regression (see $\mathrm{SI}$ for details on the calculation). Figure 7A shows the lifetimes of the optical signals at 460,600 and $800 \mathrm{~nm}$ for $1 \mathrm{rO} \mathrm{O}_{x}$ both with and without $\mathrm{H}_{2} \mathrm{O}_{2}$. In the presence of $\mathrm{H}_{2} \mathrm{O}_{2}$, the decay of the optical signal is the fastest around the onset of the redox transition 2 ( $\sim 1.1 \mathrm{~V} v s$. $\mathrm{RHE}, i R_{u}$ corrected), and is faster than without $\mathrm{H}_{2} \mathrm{O}_{2}$ at the same potential. This further proves the conclusions above that the redox state $\operatorname{Ir}(4+)$, formed at this potential range, triggers the two-electron oxidation of $\mathrm{H}_{2} \mathrm{O}_{2}$, and thus $\operatorname{Ir}(4+)$ is reduced back to the OCP redox state by $\mathrm{H}_{2} \mathrm{O}_{2}$. The calculation of the redox state lifetimes in $\mathrm{IrO}_{x}$ with and without $\mathrm{H}_{2} \mathrm{O}_{2}$ from the optical signal decay, therefore, confirms the trends observed in spectroelectrochemical measurements, and provides an experimental method to calculate directly oxidation kinetics.

A

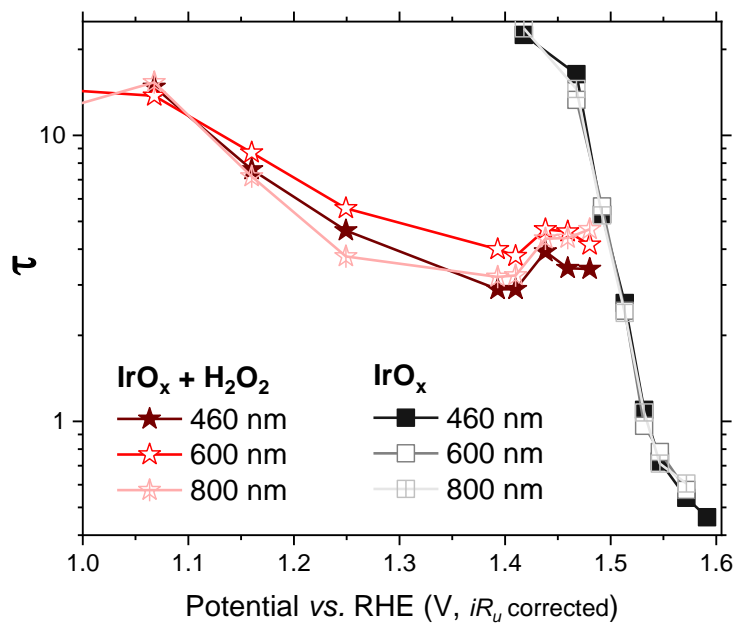

B

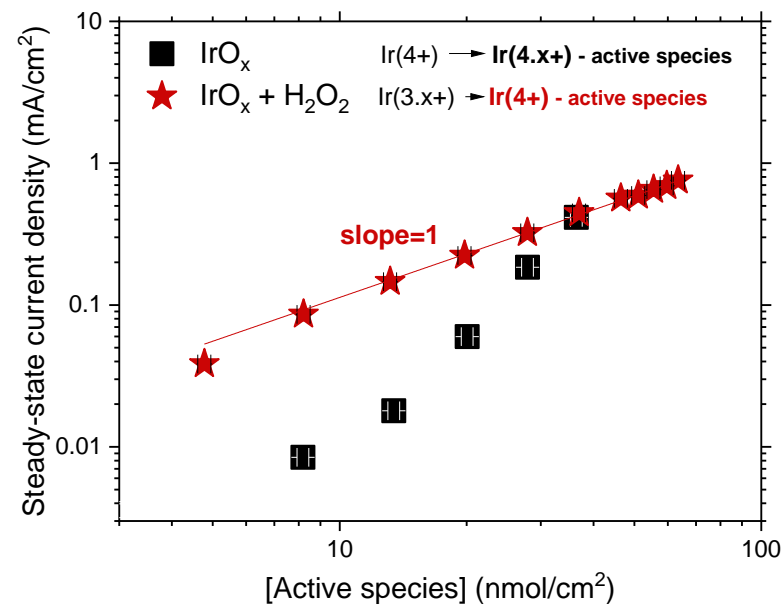

Figure 7. (A) Lifetimes derived from the decay of the optical signal over potential of $\mathrm{IrO}_{x}$ with and without $20 \mathrm{mM}$ $\mathrm{H}_{2} \mathrm{O}_{2}$. (B). Steady-state current plotted against the concentration of active species derived from the deconvoluted optical signal. The active species of $\operatorname{IrO} \mathrm{x}_{x}$ is considered $\operatorname{Ir}(\mathbf{4} . \mathbf{x}+)$ in acid solution and $\operatorname{Ir}(\mathbf{3} \cdot \mathbf{x +})$ in the presence of $\mathrm{H}_{2} \mathrm{O}_{2}$. All the measurements were done in $0.1 \mathrm{M} \mathrm{HClO}_{4}$ aqueous solution at $\mathrm{pH} 1.2$.

To investigate the dependence of the kinetics on the concentration of active species, a log-log plot of current versus the density of active species is shown in Figure 7B. The active species concentration was measured from the deconvoluted spectroelectrochemical absorption of the corresponding redox transition (redox transition 2 with $\mathrm{H}_{2} \mathrm{O}_{2}, \operatorname{Ir}(\mathbf{3} . \mathbf{x +}) \rightarrow \operatorname{Ir}(\mathbf{4 +})$, and redox transition 3 without, $\operatorname{Ir}(\mathbf{4 +}) \rightarrow \operatorname{Ir}(\mathbf{4 . x +})$, in Figures S3-4 and S7). Two other ways to measure the optical signal of the concentration of active states were based on potential steps applied cyclically, between a potential $E_{n}$ and OCP (SP-SEC, Figure 4) or between $E_{n}$ and the potential of formation of the active species 
(Scheme S1). In $\mathrm{IrO}_{x}$ without $\mathrm{H}_{2} \mathrm{O}_{2}$, the relationship between the steady-state current and the concentration has a stronger dependence on the concentration of active species, with a greater variability throughout the different measurements. This variability can be attributed to the coexistence of multiple redox states at high potential such as $\operatorname{Ir}(\mathbf{4 +})$ and $\operatorname{Ir}(\mathbf{4} . \mathbf{x +})$ and to the resulting complexity of the optical signal. In contrast, the samples of $\mathrm{IrO}_{x}$ in $20 \mathrm{mM} \mathrm{H}_{2} \mathrm{O}_{2}$ have a simple dependency between the steady-state current and the concentration of active species $\operatorname{Ir}(4+)$ with a slope equal to one, which combined with the independence of the lifetime versus potential above $1.1 \mathrm{~V}$ vs. RHE (Figure 7A) suggests a first order reaction rate of $\mathrm{IrO}_{\mathrm{x}}$ in the presence of $\mathrm{H}_{2} \mathrm{O}_{2}$. This slope can be understood as the order of the reaction, and would suggest that the rate-limiting step to evolve one molecule of $\mathrm{O}_{2}$ from $\mathrm{H}_{2} \mathrm{O}_{2}$ is based on a one-electron oxidation of an active species.

\section{Discussion}

Determining the oxygen evolution reaction mechanism and kinetics of heterogeneous catalysts is specially challenging because a diversity of mechanisms is possible and can occur simultaneously, leading to a complex mixture of intermediate states under catalytic steady-state conditions. Another complication is to determine which atoms or states are catalytically active and if they are localised at the surface. Herein, we have managed to get a useful insight into the redox chemistry of $\mathrm{IrO}_{x} \mathrm{combining}$ optical and electrochemical time-resolved measurements. From the spectroelectrochemical data, we have been able to identify different redox states and quantify their concentration. Furthermore, by monitoring the optical signal under catalytic conditions and its decay after turning the potential off, we provide a perspective on the steady-state concentrations and intrinsic kinetics not available from electrochemically measured current densities alone.

From optical and electrochemical data of $\mathrm{IrO}_{x}$ under applied potential, we have identified three redox transitions and three redox states beyond the starting redox state at the open circuit potential (Figures 1 and 2). With a model based on the Lambert Beer law and Gaussian distributions of concentration over potential, we can fit the real experimental data accurately, and we have used it to deconvolve the spectroelectrochemical data and derive the concentrations of each redox state at the different potentials (Figure 3). From the experimental data and the fit model, it is apparent that the absorption spectra of the three oxidised redox states are all distinct and distinguishable from the starting redox state (Figure 2). Following the literature, 6, 16, 18, 20, 28, 29, 37, 39, 42, 43 we assume that the starting state under OCP includes $1 \mathrm{r}^{3+}$ oxidation states only, and which we denotate as $\operatorname{Ir}\left(\mathbf{3}_{+}\right)$. Before the potential when the electrocatalytic current starts increasing, we detect two redox states whose optical transitions are assigned to the formation of a mixed valence state at $\sim 0.9 \mathrm{~V}$ including $1 \mathrm{Ir}^{3+}$ and $\operatorname{Ir}{ }^{4+}, \operatorname{Ir}(\mathbf{3} . \mathbf{x}+)$, followed by a redox state with a larger content of $\mathrm{Ir}^{4+}$ at $\sim 1.3 \mathrm{~V} v$ s. RHE, $\operatorname{Ir}(4+)$. Finally, the species oxidised at potentials when the current increases has been proposed to include oxidised $1 \mathrm{r}^{4+}$ oxygen species and we refer to it as $\operatorname{Ir}(\mathbf{4} . \mathbf{x +})$. Compared to the light-coloured $\operatorname{Ir}\left(\mathbf{3}_{+}\right)$, the redox states in $\mathrm{IrO} \times \mathrm{x}$ over OCP absorb in the UV-Vis as a result of these oxidations and the associated deprotonation of adsorbed ${ }^{*} \mathrm{OH}$ to form ${ }^{*} O$, which leads to the degeneracy in the $d$ orbitals of iridium and to an intervalence $d$ - $d$ transition upon light excitation. $40,41,54,65,66$ On the other hand, the molar ratio of redox transitions 1, 2 and 3 (calculated as the integral of the Gaussians in Figure $3 A$ ) is 10:9:3, assuming that each charge extracted from the film is related to one-electron oxidation process in a different Ir centre. Therefore, considering that the changes to the UV-Vis absorption of $\mathrm{IrO}_{\mathrm{x}}$ are related to deprotonation processes, the three redox transitions, assigned to the partial oxidation of Ir centres, must involve active species that are either at 
the electrode-electrolyte interface or, given the porous and nanostructured nature of the films, accessible to the electrolyte.

The reactivity and kinetics of the redox states in $\mathrm{IrO}_{x}$ have been analysed in $0.1 \mathrm{M} \mathrm{HClO}_{4}$ aqueous solution with and without $\mathrm{H}_{2} \mathrm{O}_{2}$ at $\mathrm{pH} 1.2$ directly using open circuit step-potential spectroelectrochemistry wherein decay kinetics were measured after turning the applied potential off. At potentials up to $\sim 1.2 \mathrm{~V} v s$. RHE ( $i R_{u}$ corrected), we do not detect any optical signal when applying increasingly oxidising potentials between $0.7 \mathrm{~V}$ and $1.1 \mathrm{~V}$ from OCP, which means that the redox states formed at these potentials do not oxidize water and but rather accumulate in the film (Figure 5). On applying potentials greater than $1.2 \mathrm{~V}$ from OCP, a distinct optical signal is detected, assigned to $\operatorname{Ir}(\mathbf{4 +}) \rightarrow \mathbf{I r}(\mathbf{4} \cdot \mathbf{x +})$. The differential spectrum during the open circuit decay from these positive potentials resembles the inverse of the combination of the optical changes during redox transition 2 $(\mathbf{I r}(\mathbf{3 . x}+) \rightarrow \mathbf{I r}(\mathbf{4 +}))$ and redox transition $3(\mathbf{I r}(\mathbf{4 +}) \rightarrow \operatorname{Ir}(\mathbf{4} . \mathbf{x}+))$ (Figure 3B). Considering the overlap between the increase in steady-state current and the redox transition 3 , these results indicate that the resulting state from redox transition $3, \operatorname{Ir}(\mathbf{4} . \mathbf{x +})$, triggers the oxidation of water and that, upon decay to open circuit, it is reduced back to $\operatorname{Ir}(\mathbf{3} . \mathbf{x +})$, the redox state present at the start of redox transitions 2 and 3 . In other words, the redox states $\operatorname{Ir}(\mathbf{4} . \mathbf{x +})$ reduces to $\operatorname{Ir}(\mathbf{4 +})$ and $\operatorname{Ir}(\mathbf{3} \cdot \mathbf{x +})$ upon water oxidation with the potential-limiting step for water oxidation being the formation of $\operatorname{Ir}(\mathbf{4} . \mathbf{x +})$. This is compatible with some of the mechanisms proposed in the literature (Scheme 1). ${ }^{18,22,25,27,32,42,43,49,67}$ On the other hand, the $\operatorname{Ir}(4+)$ formed at potentials 1.1-1.4 V can catalyse the kinetically less challenging two-electron oxidation of $\mathrm{H}_{2} \mathrm{O}_{2}$ to $\mathrm{O}_{2}$ while reducing back to $\operatorname{Ir}(\mathbf{3} \cdot \mathbf{x}+)$, as confirmed by the differential absorption (Figure S8), steady-state current (Figure $6 \mathrm{~A}$ ) and open circuit optical signal decays (Figure $5 \mathrm{~B}$ ) at $\sim 1.3 \mathrm{~V}$ vs. RHE (iR $R_{u}$ corrected) in the presence of $\mathrm{H}_{2} \mathrm{O}_{2}$. Since, $\mathrm{H}_{2} \mathrm{O}_{2}$ oxidation does not require the formation of an $\mathrm{O}$ $\mathrm{O}$ bond, this experimental result also suggests that the rate-determining step for water oxidation on $\mathrm{IrO} \mathrm{O}_{x}$ is $\mathrm{O}-\mathrm{O}$ bond formation, which requires the presence of more oxidized Ir-centres compare to $\mathrm{H}_{2} \mathrm{O}_{2}$ oxidation. This finding is also consistent with previous theoretical calculations of the OER ratedetermining step on $\mathrm{IrO}_{2}$ surfaces. ${ }^{22,27}$

The optical signal lifetime over potential (Figure $7 \mathrm{~A}$ ) can be directly related to the intrinsic OER activity of the $\mathrm{IrO}_{x}$ catalyst because it is directly related to the concentration of redox states in the material. In the aqueous acid conditions used in this work, the lifetimes of oxidized states become increasingly shorter after $1.2 \mathrm{~V} v s$. RHE and start plateauing at $>1.5 \mathrm{~V} v s$. RHE ( $i R_{u}$ corrected). At $1.5 \mathrm{~V}$ vs. RHE, both the lifetime (Figure 7A) and the reaction rate constant of the detected redox states (i.e., the inverse of the lifetime) are around 1 ( $\mathrm{s}$ and $\mathrm{s}^{-1}$ respectively). This reaction rate constant is proportional to the turnover frequency (TOF) by a factor that depends on the number of active species required to evolve one oxygen molecule. The activity of heterogeneous electrocatalysts and iridium oxides is usually expressed as gravimetric current density or specific current density normalized to the surface area. The turnover frequency can be estimated from the reported gravimetric current densities by assuming that all the iridium atoms are active (this assumption is not required for the optical decay analysis herein). ${ }^{68}$ For iridium oxides measured under similar conditions and $\mathrm{pH}$, the TOFs per Ir centre, calculated assuming all Ir centres in the sample are active, are slightly slower than the TOFs derived herein from the optical signal lifetimes of active Ir states. ${ }^{18}$ Alternatively, if single crystal surfaces of $\mathrm{IrO}_{2}(110)$ are considered with all surface CUS Ir active, the resulting TOFs per surface Ir centre are also smaller than as measured in this work, being around $0.02 \mathrm{~s}^{-1}$ at $1.6 \mathrm{~V}$ vs. RHE. ${ }^{18,34,69,70}$ It is important to note that the lifetimes of active Ir states determined herein from the optical signal decay (Figure 7A) do not require any assumption about proportion of Ir centres which are catalytically active. Moreover, our spectroelectrochemical data indicate the density of active Ir states increases with applied 
potential (at least over the potential range studied), with our kinetic data further indicating the TOFs per active Ir states also accelerates, resulting in the observed sharp turn on of catalytic current. On the other hand, the TOFs calculated from the optical signal are similar to the turnover frequencies of Irbased molecular catalysts at $\mathrm{pH}$ 1, which are around 1-3 $\mathrm{s}^{-1} .18,34,69,70 \mathrm{In}$ amorphous $\mathrm{IrO}_{x}$ and molecular iridium complexes, the similarity between the TOF calculated from the optical signal lifetime and from the current density per mol of iridium would indicate a high iridium utilisation in both electrocatalysts. The latter shows that fast reaction rates and high current densities can only be supported with high effective surface areas maximising the exposure of all iridium sites.

In this study we have shown that current density increases in parallel with the formation of reactive states of $\mathrm{IrO}_{x}$ (Figure $3 \mathrm{~A}$ ), with different dependencies in the presence and absence of $\mathrm{H}_{2} \mathrm{O}_{2}$ resulting from different redox states and different reaction kinetics explaining the different electrocatalytic behaviour. The independence of the lifetime versus potential (Figure 7A) combined with the dependence of the steady-state current on the concentration of active species (Figure 7B) suggests a first order reaction rate of $\mathrm{IrO}_{x}$ in the presence of $\mathrm{H}_{2} \mathrm{O}_{2}$ above $1.1 \mathrm{~V} v$ s. $\mathrm{RHE}$. This contrasts with the strong potential dependence of the water oxidation reaction kinetics, potentially indicative of a higher order reaction mechanism for water oxidation involving the co-operative interaction of different intermediate states based on $\operatorname{Ir}^{4 . x+}$. Such higher order water oxidation reaction kinetics have also been reported for other metal oxide (photo)electrocatalysts. $.^{25}, 49$ Different reaction mechanisms for water and $\mathrm{H}_{2} \mathrm{O}_{2}$ oxidation are also indicated by the difference in their Tafel slopes determined from plots of log current versus potential (Figure S9) .68 For $\mathrm{IrO}_{x}$ in water at $\mathrm{pH} 1.2$, the Tafel slope is $59 \mathrm{mV} / \mathrm{dec}$, similar to $\sim 60 \mathrm{mV} / \mathrm{dec}$ measured in other $\mathrm{IrO}_{x}$ electrocatalysts at the same potential range. ${ }^{26,45,71,72} \mathrm{~A}$ larger Tafel slope of $220 \mathrm{mV} /$ decade is observed in the presence of $\mathrm{H}_{2} \mathrm{O}_{2}$, which is consistent with the lower dependence of $\tau$ upon applied potential observed in Figure 7. Notably, these data indicate that cooperative interactions between oxidized Ir states can be critical to understanding the water oxidation mechanism on $\mathrm{IrO}_{\mathrm{x}}$, consistent with recent reports that the activation energy for water oxidation can be dependent upon the surface density of oxidised Ir states. ${ }^{26,45,71,72}$ Whilst the data herein are limited in potential range (it is interesting to note that water oxidation reaction kinetics in Figure $7 a$ appear to plateau for potentials $>1.5 \mathrm{~V}$ vs. RHE, although bubble formation prevented further analysis), the clear difference in reaction kinetics between water and $\mathrm{H}_{2} \mathrm{O}_{2}$ kinetics is indicative of different reaction mechanisms, with water oxidation being dependent upon co-operative interactions between surface oxidised intermediates. The kinetics of $\mathrm{H}_{2} \mathrm{O}_{2}$ oxidation are facilitated relative to $\mathrm{H}_{2} \mathrm{O}$ oxidation into $\mathrm{O}_{2}$ probably because of the circumvention of ${ }^{*} \mathrm{OOH}$ formation in $\mathrm{H}_{2} \mathrm{O}_{2}$, which is presumably the rate determining step in water oxidation and is already formed in the $\mathrm{H}_{2} \mathrm{O}_{2}$ molecule. ${ }^{27}$ The higher order of reaction and cooperative effect between $\mathrm{Ir}^{4 . x+}$ centres in catalysing water oxidation can also be attributed to the $\mathrm{O}-\mathrm{O}$ bond formation step, since this behaviour is not observed for $\mathrm{H}_{2} \mathrm{O}_{2}$ oxidation. This insight into the intrinsic reaction kinetics from our spectroelectrochemical data builds on the interpretations of widely applied Tafel and Butler-Volmer analyses for water oxidation, and the experimental approach can be readily applied to disordered metal oxide electrocatalysts such as $\mathrm{IrO}_{\mathrm{x}}$ which are of increasing interest to enhance the performance and cost effectiveness of electrolysers. 


\section{Acknowledgements}

J.R.D., I.E.L.S. and R.R.R. acknowledge funding from bp-ICAM. C.B-G. was supported by an EPSRC studentship. I.E.L.S. acknowledges funding from the European Research Council (ERC) under the EU's Horizon 2020 research and innovation programme (grant agreement 866402). S.A.J.H. thanks the EPSRC for a Centre for Doctoral Training post-graduate studentship (EP/L016702/1).

\section{Conflict of Interest}

There is no conflict of interest to declare.

\section{References}

1. Z. W. Seh, J. Kibsgaard, C. F. Dickens, I. Chorkendorff, J. K. Nørskov and T. F. Jaramillo, Science, 2017, 355.

2. S. Haussener, C. Xiang, J. M. Spurgeon, S. Ardo, N. S. Lewis and A. Z. Weber, Energy Environ. Sci., 2012, 5, 9922.

3. A. Marshall, B. Børresen, G. Hagen, M. Tsypkin and R. Tunold, Energy, 2007, 32, 431-436.

4. M. Carmo, D. L. Fritz, J. Mergel and D. Stolten, Int. J. .Hydrog. Energy, 2013, 38, 4901-4934.

5. M. Bernt, A. Siebel and H. A. Gasteiger, J. Electrochem. Soc., 2018, 165, F305-F314.

6. O. Kasian, J. P. Grote, S. Geiger, S. Cherevko and K. J. J. Mayrhofer, Angew. Chem. Int. Ed. , 2018, 57, 2488-2491.

7. H. Dau, C. Limberg, T. Reier, M. Risch, S. Roggan and P. Strasser, ChemCatChem, 2010, 2, 724-761.

8. A. Grimaud, O. Diaz-Morales, B. Han, W. T. Hong, Y. L. Lee, L. Giordano, K. A. Stoerzinger, M. T. M. Koper and Y. Shao-Horn, Nat. Chem., 2017, 9, 457-465.

9. Z. Taie, X. Peng, D. Kulkarni, I. V. Zenyuk, A. Z. Weber, C. Hagen and N. Danilovic, ACS Appl. Mater. Interfaces, 2020, 12, 52701-52712.

10. K. Ayers, N. Danilovic, R. Ouimet, M. Carmo, B. Pivovar and M. Bornstein, Annu. Rev. Chem. Biomol. Eng., 2019, 10, 219-239.

11. D. Chandra, T. Sato, Y. Tanahashi, R. Takeuchi and M. Yagi, Energy, 2019, 173, 278-289.

12. H. Jang and J. Lee, J. Energy Chem., 2020, 46, 152-172.

13. K. Yamanaka, Jpn. J. Appl. Phys., 1989, 28, 632-637.

14. A. R. Zeradjanin, A. A. Topalov, Q. Van Overmeere, S. Cherevko, X. Chen, E. Ventosa, W. Schuhmann and K. J. J. Mayrhofer, RSC Advances, 2014, 4.

15. M. Ledendecker, S. Geiger, K. Hengge, J. Lim, S. Cherevko, A. M. Mingers, D. Göhl, G. V. Fortunato, D. Jalalpoor, F. Schüth, C. Scheu and K. J. J. Mayrhofer, Nano Res., 2019, 12, 2275-2280.

16. O. Kasian, S. Geiger, T. Li, J.-P. Grote, K. Schweinar, S. Zhang, C. Scheu, D. Raabe, S. Cherevko, B. Gault and K. J. J. Mayrhofer, Energy Environ. Sci., 2019, 12, 3548-3555.

17. S. Geiger, O. Kasian, B. R. Shrestha, A. M. Mingers, K. J. J. Mayrhofer and S. Cherevko, J. Electrochem. Soc., 2016, 163, F3132-F3138.

18. S. Geiger, O. Kasian, M. Ledendecker, E. Pizzutilo, A. M. Mingers, W. T. Fu, O. Diaz-Morales, Z. Li, T. Oellers, L. Fruchter, A. Ludwig, K. J. J. Mayrhofer, M. T. M. Koper and S. Cherevko, Nat. Catal., 2018, 1, 508-515.

19. S. Cherevko, S. Geiger, O. Kasian, A. Mingers and K. J. J. Mayrhofer, J. Electroanal. Chem., 2016, 773, 69-78.

20. S. Cherevko, S. Geiger, O. Kasian, A. Mingers and K. J. J. Mayrhofer, J. Electroanal. Chem., 2016, 774, 102-110.

21. T. Li, O. Kasian, S. Cherevko, S. Zhang, S. Geiger, C. Scheu, P. Felfer, D. Raabe, B. Gault and K. J. J. Mayrhofer, Nat. Catal., 2018, 1, 300-305.

22. I. C. Man, H. Y. Su, F. Calle-Vallejo, H. A. Hansen, J. I. Martínez, N. G. Inoglu, J. Kitchin, T. F. Jaramillo, J. K. Nørskov and J. Rossmeisl, ChemCatChem, 2011, 3, 1159-1165.

23. H. A. Hansen, V. Viswanathan and J. K. Nørskov, J. Phys. Chem. C, 2014, 118, 6706-6718.

24. C. F. Dickens, C. Kirk and J. K. Nørskov, J. Phys. Chem. C, 2019, 123, 18960-18977. 
25. T. Naito, T. Shinagawa, T. Nishimoto and K. Takanabe, Inorg. Chem. Front., 2021, DOI: 10.1039/d0qi01465f.

26. C. A. Mesa, L. Francàs, K. R. Yang, P. Garrido-Barros, E. Pastor, Y. Ma, A. Kafizas, T. E. Rosser, M. T. Mayer, E. Reisner, M. Grätzel, V. S. Batista and J. R. Durrant, Nat. Chem., 2020, 12, 82-89.

27. J. Rossmeisl, Z. W. Qu, H. Zhu, G. J. Kroes and J. K. Nørskov, J. Electroanal. Chem., 2007, 607, 83-89.

28. H. Ooka, T. Takashima, A. Yamaguchi, T. Hayashi and R. Nakamura, Chem. Commun., 2017, 53, 7149-7161.

29. H. Ooka, Y. Wang, A. Yamaguchi, M. Hatakeyama, S. Nakamura, K. Hashimoto and R. Nakamura, Phys. Chem. Chem. Phys., 2016, 18, 15199-15204.

30. S. B. Sinha, D. Y. Shopov, L. S. Sharninghausen, C. J. Stein, B. Q. Mercado, D. Balcells, T. B. Pedersen, M. Reiher, G. W. Brudvig and R. H. Crabtree, J. Am. Chem. Soc., 2017, 139, $9672-$ 9683.

31. G. S. Nahor, P. Hapiot, P. Neta and A. Harriman, J. Phys. Chem., 1991, 95, 616-621.

32. Z. Pavlovic, C. Ranjan, M. van Gastel and R. Schlögl, Chem. Commun., 2017, 53, 1241412417.

33. Z. Pavlovic, C. Ranjan, Q. Gao, M. van Gastel and R. Schlögl, ACS Catal., 2016, 6, 8098-8105.

34. D. Y. Kuo, J. K. Kawasaki, J. N. Nelson, J. Kloppenburg, G. Hautier, K. M. Shen, D. G. Schlom and J. Suntivich, J. Am. Chem. Soc., 2017, 139, 3473-3479.

35. R. R. Rao, M. J. Kolb, L. Giordano, A. F. Pedersen, Y. Katayama, J. Hwang, A. Mehta, H. You, J. R. Lunger, H. Zhou, N. B. Halck, T. Vegge, I. Chorkendorff, I. E. L. Stephens and Y. ShaoHorn, Nat. Catal., 2020, 3, 516-525.

36. R. R. Rao, M. J. Kolb, N. B. Halck, A. F. Pedersen, A. Mehta, H. You, K. A. Stoerzinger, Z. Feng, H. A. Hansen, H. Zhou, L. Giordano, J. Rossmeisl, T. Vegge, I. Chorkendorff, I. E. L. Stephens and Y. Shao-Horn, Energy Environ. Sci., 2017, 10, 2626-2637.

37. V. Pfeifer, T. E. Jones, J. J. Velasco Velez, C. Massue, M. T. Greiner, R. Arrigo, D. Teschner, F. Girgsdies, M. Scherzer, J. Allan, M. Hashagen, G. Weinberg, S. Piccinin, M. Havecker, A. Knop-Gericke and R. Schlögl, Phys. Chem. Chem. Phys., 2016, 18, 2292-2296.

38. A. F. Pedersen, M. Escudero-Escribano, B. Sebok, A. Bodin, E. Paoli, R. Frydendal, D. Friebel, I. E. L. Stephens, J. Rossmeisl, I. Chorkendorff and A. Nilsson, J. Phys. Chem. B, 2018, 122, 878-887.

39. H. G. Sanchez Casalongue, M. L. Ng, S. Kaya, D. Friebel, H. Ogasawara and A. Nilsson, Angew. Chem. Int. Ed., 2014, 53, 7169-7172.

40. P. M. S. Monk, R. J. Mortimer and D. R. Rosseinsky, Cambridge University Press, 2008.

41. S. Gottesfeld, J. D. E. McIntyre, G. Beni and J. L. Shay, Appl. Phys. Lett., 1978, 33, 208-210.

42. V. Pfeifer, T. E. Jones, J. J. Velasco Velez, R. Arrigo, S. Piccinin, M. Havecker, A. Knop-Gericke and R. Schlögl, Chem. Sci., 2017, 8, 2143-2149.

43. V. Pfeifer, T. E. Jones, S. Wrabetz, C. Massue, J. J. Velasco Velez, R. Arrigo, M. Scherzer, S. Piccinin, M. Havecker, A. Knop-Gericke and R. Schlögl, Chem. Sci., 2016, 7, 6791-6795.

44. L. Francàs, S. Corby, S. Selim, D. Lee, C. A. Mesa, R. Godin, E. Pastor, I. E. L. Stephens, K. S. Choi and J. R. Durrant, Nat. Commun., 2019, 10, 5208.

45. H. N. Nong, L. J. Falling, A. Bergmann, M. Klingenhof, H. P. Tran, C. Spori, R. Mom, J. Timoshenko, G. Zichittella, A. Knop-Gericke, S. Piccinin, J. Perez-Ramirez, B. R. Cuenya, R. Schlögl, P. Strasser, D. Teschner and T. E. Jones, Nature, 2020, 587, 408-413.

46. M. S. Burke, L. J. Enman, A. S. Batchellor, S. Zou and S. W. Boettcher, Chem. Mat., 2015, 27, 7549-7558.

47. T. R. Eaton, M. P. Campos, K. A. Gray and J. M. Notestein, J. Catal., 2014, 309, 156-165.

48. K. A. Stoerzinger, L. Qiao, M. D. Biegalski and Y. Shao-Horn, J. Phys. Chem. Lett., 2014, 5, 1636-1641.

49. V. Pfeifer, T. E. Jones, J. J. Velasco Vélez, C. Massué, R. Arrigo, D. Teschner, F. Girgsdies, M. Scherzer, M. T. Greiner, J. Allan, M. Hashagen, G. Weinberg, S. Piccinin, M. Hävecker, A. Knop-Gericke and R. Schlögl, Surf. Interface Anal., 2016, 48, 261-273.

50. M. A. Petit and V. Plichon, Phys Chem Chem Phys, 1998, 444, 247.

51. Y. Zhang, M. Cao, H. Lv, J. Wei, Y. Gu, D. Liu, W. Zhang, M. P. Ryan and X. Wu, Electrochim. Acta, 2018, 265, 507-513.

52. S. Gottesfeld and J. D. E. McIntyre, J. Electrochem. Soc., 1979, 742-750.

53. S. Gottesfeld and S. Srinivasan, J. Electroanal. Chem., 1978, 86, 89-104.

54. P. M. S. Monk, R. J. Mortimer and D. R. Rosseinsky, VCH, 1995.

55. M. B. Robin and P. Day, 1968, 10, 247-422. 
56. K. H. Saeed, M. Forster, J. F. Li, L. J. Hardwick and A. J. Cowan, Chem. Commun., 2020, 56, $1129-1132$.

57. A. Walsh, A. A. Sokol, J. Buckeridge, D. O. Scanlon and C. R. A. Catlow, Nat. Mater., 2018, 17, 958-964.

58. A. Minguzzi, C. Locatelli, O. Lugaresi, E. Achilli, G. Cappelletti, M. Scavini, M. Coduri, P. Masala, B. Sacchi, A. Vertova, P. Ghigna and S. Rondinini, ACS Catal., 2015, 5, 5104-5115.

59. V. A. Saveleva, L. Wang, D. Teschner, T. Jones, A. S. Gago, K. A. Friedrich, S. Zafeiratos, R. Schlögl and E. R. Savinova, J. Phys. Chem. Lett., 2018, 9, 3154-3160.

60. E. R. Kötz, H. Neff and K. Müller, J. Electroanal. Chem. Interf. Electrochem., 1986, 215, 331 344.

61. R. Kötz, H. Neff and S. Stucki, J. Electrochem. Soc., 1984, 131, $72-77$.

62. D. Maric and J. P. Burrows, J. Phys. Chem., 1996, 100, 8645-8659.

63. J. Grunenberg, Weinheim: Wiley-VCH, 2010.

64. D. Loco and L. Cupellini, Int. J. Quantum Chem., 2019, 119.

65. G. Beni, C. E. Rice and J. L. Shay, J. Electrochem. Soc., 1980, 127, 1342-1348.

66. W. C. Dautremont-Smith, G. Beni, L. M. Schiavone and J. L. Shay, Appl. Phys. Lett., 1979, 35, 565-567.

67. M. T. M. Koper, J. Solid State Electrochem.y, 2012, 17, 339-344.

68. A. J. Bard and L. R. Faulkner, John Wiley \& Sons, Inc., 2001, $2^{\text {nd }}$ Edition.

69. O. Diaz-Morales, T. J. Hersbach, D. G. Hetterscheid, J. N. Reek and M. T. Koper, J. Am. Chem. Soc., 2014, 136, 10432-10439.

70. S. Cherevko, S. Geiger, O. Kasian, N. Kulyk, J.-P. Grote, A. Savan, B. R. Shrestha, S. Merzlikin, B. Breitbach, A. Ludwig and K. J. J. Mayrhofer, Catal. Today, 2016, 262, 170-180.

71. R. R. Rao, I. E. L. Stephens and J. R. Durrant, Joule, 2021, 5, 16-18.

72. S. W. Boettcher and Y. Surendranath, Nat. Catal., 2021, 4, 4-5. 